\title{
Inappropriate use of antibiotics for childhood diarrhea case management - Kenya, 2009-2016
}

\author{
Chulwoo Rhee ${ }^{*}$, George Aol ${ }^{2}$, Alice Ouma ${ }^{3}$, Allan Audi ${ }^{2}$, Shadrack Muema ${ }^{3}$, Joshua Auko ${ }^{2}$, Richard Omore ${ }^{3}$, \\ George Odongo', Ryan E. Wiegand', Joel M. Montgomery', Marc-Alain Widdowson ${ }^{1,4}$, Ciara E. O'Reilly ${ }^{5}$, \\ Godfrey Bigogo ${ }^{2}$ and Jennifer R. Verani ${ }^{1,4}$
}

\begin{abstract}
Background: Antibiotics are essential to treat for many childhood bacterial infections; however inappropriate antibiotic use contributes to antimicrobial resistance. For childhood diarrhea, empiric antibiotic use is recommended for dysentery (bloody diarrhea) for which first-line therapy is ciprofloxacin. We assessed inappropriate antibiotic prescription for childhood diarrhea in two primary healthcare facilities in Kenya.
\end{abstract}

Methods: We analyzed data from the Kenya Population Based Infectious Disease Surveillance system in Asembo (rural, malaria-endemic) and Kibera (urban slum, non-malaria-endemic). We examined records of children aged 259 months with diarrhea ( $\geq 3$ loose stools in 24 h) presenting for care from August 21, 2009 to May 3, 2016, excluding visits with non-diarrheal indications for antibiotics. We examined the frequency of antibiotic overprescription (antibiotic prescription for non-dysentery), under-prescription (no antibiotic prescription for dysentery), and inappropriate antibiotic selection (non-recommended antibiotic). We examined factors associated with overprescription and under-prescription using multivariate logistic regression with generalized estimating equations.

Results: Of 2808 clinic visits with diarrhea in Asembo, 2685 (95.6\%) were non-dysentery visits and antibiotic overprescription occurred in 52.5\%. Of 4697 clinic visits with diarrhea in Kibera, 4518 (96.2\%) were non-dysentery and antibiotic over-prescription occurred in 20.0\%. Antibiotic under-prescription was noted in 26.8 and $73.7 \%$ of dysentery cases in Asembo and Kibera, respectively. Ciprofloxacin was used for $11 \%$ of dysentery visits in Asembo and $0 \%$ in Kibera. Factors associated with over- and under-prescription varied by site. In Asembo a discharge diagnosis of gastroenteritis was associated with over-prescription (adjusted odds ratio [aOR]:8.23, 95\% confidence interval [95\%Cl]: 3.68-18.4), while malaria diagnosis was negatively associated with antibiotic over-prescription (aOR 0.37, 95\%Cl: 0.25-0.54) but positively associated with antibiotic under-prescription (aOR: 1.82, 95\%Cl: 1.05-3.13). In Kibera, over-prescription was more common among visits with concurrent signs of respiratory infection (difficulty breathing; aOR: $3.97,95 \% \mathrm{Cl}: 1.28-12.30$, cough: aOR: 1.42, 95\%Cl: 1.06-1.90) and less common among children aged $<1$ year (aOR: 0.82, 95\%Cl: 0.71-0.94).

Conclusions: Inappropriate antibiotic prescription was common in childhood diarrhea management and efforts are needed to promote rational antibiotic use. Interventions to improve antibiotic use for diarrhea should consider the influence of malaria diagnosis on clinical decision-making and address both over-prescription, under-prescription, and inappropriate antibiotic selection.

Keywords: Diarrhea, Guideline adherence, Antibiotics, Dysentery

\footnotetext{
* Correspondence: yvw7@cdc.gov

'Division of Global Health Protection, Center for Global Health, Centers for

Disease Control and Prevention, Atlanta, GA, USA

Full list of author information is available at the end of the article
}

(c) The Author(s). 2019 Open Access This article is distributed under the terms of the Creative Commons Attribution 4.0 International License (http://creativecommons.org/licenses/by/4.0/), which permits unrestricted use, distribution, and reproduction in any medium, provided you give appropriate credit to the original author(s) and the source, provide a link to the Creative Commons license, and indicate if changes were made. The Creative Commons Public Domain Dedication waiver (http://creativecommons.org/publicdomain/zero/1.0/) applies to the data made available in this article, unless otherwise stated. 


\section{Background}

Inappropriate antibiotic use, which includes prescribing unnecessary antibiotics, prescribing incorrect antibiotics, and not prescribing antibiotics when needed, is a major public health problem [1]. Overuse and misuse of antibiotics adds to the cost of treatment, risks adverse reactions and enhances the development of resistant pathogens [2]. According to a recent report on global antimicrobial resistance by the World Health Organization (WHO), antimicrobial resistance among pathogens responsible for common infections is alarmingly high [3]. In order to combat pressing public health concerns of antimicrobial resistance, a global action plan was adopted by the World Health Assembly in 2015 [4]. Increasing adherence to standard treatment guidelines has been highlighted as a core action to promote rational use of antibiotics $[5,6]$.

Antibiotics are frequently prescribed for common clinical syndromes, yet are not recommended for the majority of diarrheal episodes. For childhood diarrhea in resource-poor settings, WHO guidelines for the Integrated Management of Childhood Illness (IMCI) recommend empirical use of antibiotics only for dysentery, or bloody diarrhea [7], including high HIV prevalence settings [8]. For dysentery, antibiotics are intended to treat shigellosis which causes the most episodes of bloody diarrhea in children $[9,10]$, and ciprofloxacin is the recommended first-line agent. The recommended management of watery childhood diarrhea is oral rehydration and zinc [9] as they are most commonly caused by viral infections.

Diarrheal disease remains a major cause of morbidity and mortality among children under 5 years in Kenya [11], and Shigella bacteria has been frequently isolated in patients with dysentery, $66 \%$ for toddlers and $78 \%$ for children [12]. The Ministry of Health's recommended management of diarrhea in Kenya is consistent with the WHO IMCI guidelines [13]. Although antibiotic overuse has been reported to be common in Kenya [14], little is known about specific antibiotic prescription practices for the management of childhood diarrhea in primary care facilities and their driving factors. In the current analysis, we aimed to measure the prevalence of inappropriate antibiotic prescription for childhood diarrhea case management and to determine factors associated with antibiotic over-prescription and underprescription in one urban and one rural primary care facility in Kenya.

\section{Methods}

\section{Study setting and data collection}

We used data from the ongoing Population-Based Infectious Disease Surveillance (PBIDS) platform of the Kenya Medical Research Institute (KEMRI) and U.S. Centers for Disease Control and Prevention (CDC) in
Kenya, described elsewhere [15]. In brief, approximately 25,000 individuals are under surveillance in each of two sites; a rural, sparsely populated, malaria-endemic setting in western Kenya (Asembo) and an urban, non-malaria endemic, densely populated, informal settlement in Nairobi, Kenya (Kibera). PBIDS participants receive free medical care for acute illness, including medications, at centrally located surveillance clinics. In Asembo all PBIDS households are within a $\sim 5 \mathrm{~km}$ radius of the St. Elizabeth Lwak Mission Hospital, which offers predominantly outpatient services but also has a small inpatient ward. In Kibera all PBIDS households are within $\mathrm{a} \sim 1$ $\mathrm{km}$ radius of the Tabitha clinic, which offers outpatient services only.

At the surveillance clinics, a structured questionnaire is administered by trained study staff to collect information on medical history including use of prophylactic cotrimoxazole and antiretroviral medication, and reported clinical symptoms, followed by detailed history taking and physical examinations performed by clinical officers. All data are captured in an electronic medical record system, including clinical diagnoses, any medications prescribed and if the patient illness met the case definitions of one of the four syndromes under surveillance (acute respiratory infection, acute lower respiratory infection, diarrhea, and acute febrile illness) [15]. Patients meeting the case definition for diarrhea (3 or more loose stools in the prior $24 \mathrm{~h}$ ), are asked to provide a whole stool sample; however, stool testing results are not available immediately to guide clinical management during the clinic visit at which they are collected due to processing times. In addition, both facilities conduct on-site microscopic examination of stool for ova and parasites, and peripheral blood smear for malaria at the discretion of the clinician but not systematically for surveillance purposes.

\section{Inclusion, exclusion, and outcome criteria}

We identified surveillance records of clinic visits of PBIDS participants aged 2-59 months presenting with diarrhea from August 21, 2009 to May 3, 2016. We then excluded records in which there was a non-diarrheal indication for antibiotics per IMCI guidelines, including those meeting criteria for possible serious bacterial infection, severe pneumonia or very severe disease, pneumonia, very severe febrile disease, and acute ear infection [7]. Although IMCI also recommends antibiotics for mastoiditis and severe complicated measles, the surveillance data did not contain the necessary variables to identify such cases based on clinical criteria; however visits with a discharge diagnosis of either of these were excluded. We also excluded records with a discharge diagnosis of meningitis, pneumonia, acute otitis media, or 
bacteremia, regardless of whether IMCI criteria for antibiotics were met. Since we were interested in the use of antibiotics for diarrhea based on clinical signs and symptoms, we also excluded records with a discharge diagnosis of amoebiasis or giardiasis, since microscopy results may have prompted prescription of antibiotics for those cases. Clinic visits with missing variables were excluded as we weren't able to assess antibiotic indication per IMCI guidelines.

The remaining diarrheal cases were categorized into dysentery and non-dysentery, based on parental report and/or clinician observation of blood in the stool. We reviewed treatment data for any antibiotics prescribed during the clinical visit encounter. Antibiotic over-prescription was defined as an antibiotic prescription for non-dysentery cases and under-prescription as no antibiotic prescription for dysentery cases. Inappropriate antibiotic selection was defined as prescription of non-recommended antibiotic for dysentery cases by the guidelines [16, 17].

\section{Statistical analysis}

Statistical analyses were performed separately for each site due to heterogeneity between the two settings. Comparison between groups were performed by Pearson chi-squared or Fisher's exact test for categorical variables and Student's $t$-test for continuous variables. Multivariate logistic regression was used to identify factors associated with antibiotic over-prescription and under-prescription for each site. For multivariate analyses, variables were initially selected using a cut-off $p$-value of 0.2 based on univariate analyses and final multivariate models were constructed using the least absolute shrinkage and selection operator regression [18]. Interaction terms were explored for any statistical significance and multiple stopping criteria were used to identify the best fit model. To account for clustering of antibiotic prescription tendency by clinical officers, we also adjusted for the standard errors using generalized estimating equations [19]. All statistical analyses were performed in SAS Software version 9.3 (SAS Institute, Inc., Cary, NC). All tests were two-sided and used the $5 \%$ level of significance.

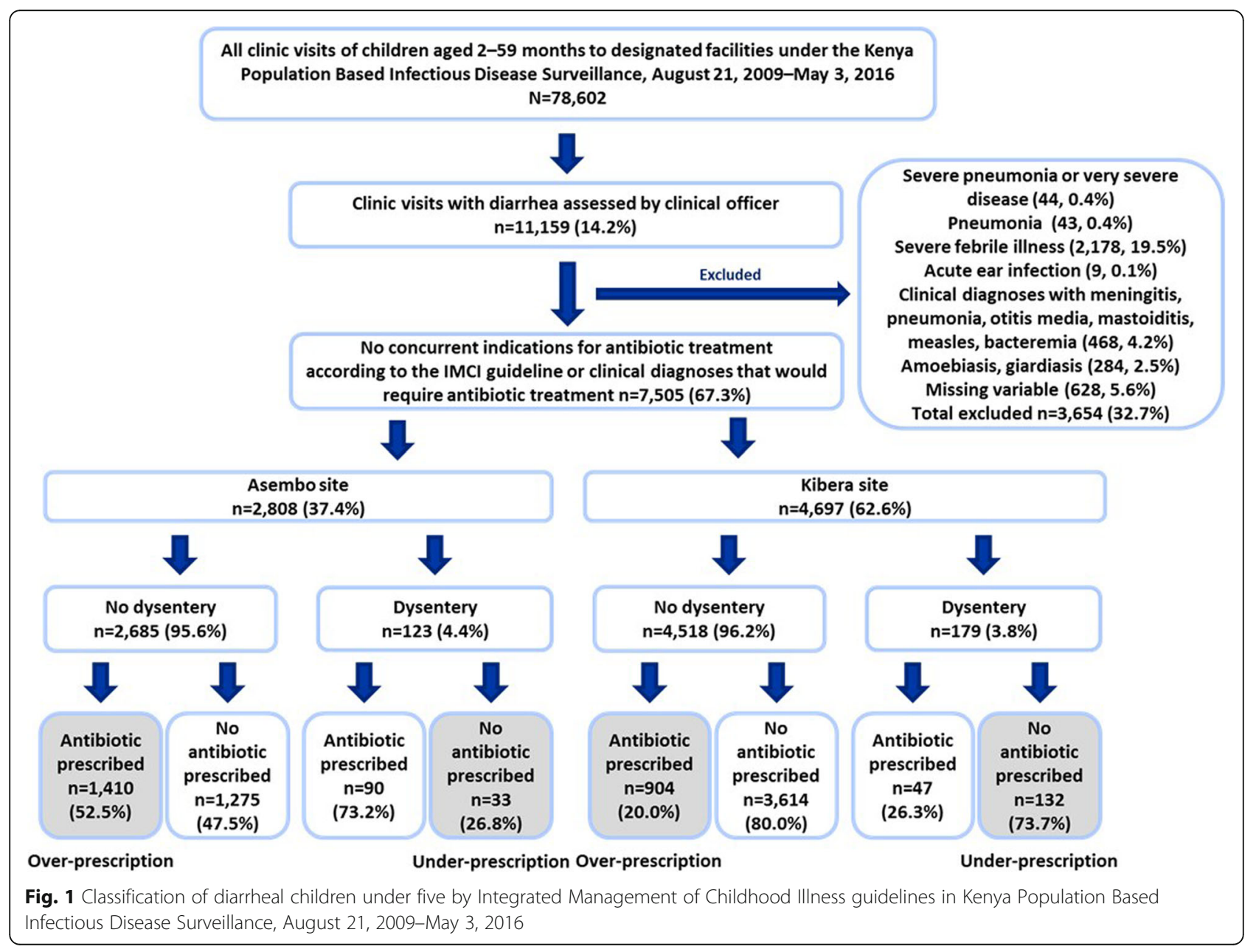




\section{Results}

Of 78,602 clinic visits of children aged 2-59 months in the study period, 11,159 (14.2\%) were clinic visits of patients with diarrhea (Fig. 1). We excluded 3654 (32.7\%) clinic visits with a non-diarrheal indication for antibiotics as defined on the Additional file 1:Table S1, and $284(2.5 \%)$ with a diagnosis of giardiasis or amoebiasis, leaving 7505 (67.3\%) visits for final analyses, including 2808 and 4697 visits for Asembo and Kibera respectively. In Asembo, 2685 (95.6\%) visits were non-dysentery and antibiotic over-prescription prevalence was 52.5\%. Of 123 (4.4\%) dysentery visits in Asembo, antibiotic under-prescription prevalence was $26.8 \%$. In Kibera, 4518 (96.2\%) visits were non-dysentery and antibiotic over-prescription prevalence was $20.0 \%$. Of 179 (3.8\%) dysentery visits in Kibera, antibiotic under-prescription prevalence was $73.7 \%$. During the study period, Asembo had 41 clinical officers who treated 46 diarrheal children on average (range 1-397) and Kibera had 37 clinical officers who treated 127 diarrheal children on average (range 1-1199).

Antibiotic over-prescription was more common in Asembo than Kibera $(52.5 \%$ vs. $20.0 \%, p<0.01)$ and factors associated with over-prescription varied between the sites (Tables 1, 2). In Asembo, antibiotic over-prescription was positively associated with a discharge diagnosis of gastroenteritis [OR: 8.23 95\% CI: 3.68-18.40] but negatively associated with a diagnosis of malaria [OR: 0.37 95\%CI: 0.25-0.54] and concurrent oral rehydration solution (ORS) treatment [OR: 0.49 95\%CI: 0.33-0.71]. We found a significant interaction between gastroenteritis diagnosis and concurrent ORS treatment in Asembo (Additional file 1: Table S2). The ORS treatment prescription with documented gastroenteritis diagnosis was negatively associated with antibiotic over-prescription [OR: 0.35 95\% CI: 0.22-0.54] while ORS treatment without documented gastroenteritis diagnosis was not associated with antibiotic over-prescription. In Kibera, antibiotic over-prescription was positively associated with prior antibiotic treatment at the surveillance facility within the last 14 days, measured or reported fever, cough, difficulty breathing, and abnormal auscultation findings of crackles or rales. Association with gastroenteritis diagnosis or ORS treatment was not found in Kibera. Age less than 1 year was negatively associated with antibiotic over-prescription [OR: 0.82 95\%CI: 0.71-0.94].

The proportion of visits with dysentery was similar across sites (4.4\% is Asembo and vs. $3.8 \%$ in Kibera, $p=0.22$ ), but antibiotic under-prescription was more common in Kibera than Asembo ( $73.7 \%$ vs. $26.8 \%, p<0.01$ ) (Tables 3, 4). In Asembo, under-prescription was associated with vomiting [OR: 4.36 95\%CI: 1.98-9.57] and a discharge diagnosis of malaria [OR: 1.82 95\%CI: 1.05-3.13]. In Kibera, under-prescription was positively associated with age less than 1 year [OR: 4.76 95\%CI: 1.46-15.5], and negatively associated with a discharge diagnosis of dysentery [OR: 0.10 95\%CI: 0.03-0.34].

For dysentery visits, the most common antibiotics prescribed in both sites were erythromycin, metronidazole, and nalidixic acid (Fig. 2). Cotrimoxazole was commonly prescribed in Asembo for dysentery visits, but not used in Kibera. Ciprofloxacin, the recommended agent, was prescribed in 11\% of dysentery visits in Asembo and 0\% in Kibera. For diarrheal non-dysentery visits, the commonly prescribed antibiotics were erythromycin and metronidazole in Kibera and cotrimoxazole, erythromycin and metronidazole in Asembo (Fig. 3).

\section{Discussion}

Inappropriate antibiotic prescription for childhood diarrhea management was common in both rural and urban sites in Kenya. Overall, 34.2\% of diarrhea visits to health facilities had either over-prescription, under-prescription, or inappropriate choice of antibiotics. Antibiotic over-prescription was observed more frequently in the rural, malaria-endemic area while under-prescription was more predominant in the urban, densely populated, slum area. We found little overlap in the factors associated with antibiotic over-prescription and under-prescription between two study sites. Our findings indicate that despite presence of national and international guidelines, the magnitude of antibiotic over-prescription and under-prescription, and the factors that drive them, can vary greatly between facilities.

More than $95 \%$ of diarrhea clinic visits did not warrant antibiotics. Yet we found that antibiotics were inappropriately prescribed for 2 to 5 of every 10 cases of non-dysentery diarrhea. These results are consistent with other studies that have reported frequent antibiotic over-prescription for diarrhea in resource-limited outpatient settings. A cross-sectional study assessing antibiotic prescribing practice for the management of diarrhea in Tanzania reported $54.4 \%$ of children with acute watery diarrhea were prescribed with antibiotics inappropriately [20]. Similar studies in India and Thailand reported antibiotic overuse of 71 and $55.2 \%$ respectively [21, 22]. We found over-prescription to be more common in the rural site than an urban informal settlement, which is consistent with a study of antibiotic consumption in Heilongjiang Province, China [23]. Factors such as knowledge and attitude of caregiver or distance needed to travel for clinic visit might have influenced the differences between rural and urban sites. In contrast, a study conducted in Ethiopia found no difference in antibiotics overuse between rural and urban sites [24]. Despite differences between the rural and urban settings in our study, the overall frequency of inappropriate use for diarrhea is alarming, and is likely 
Table 1 Multivariate analysis for factors associated with antibiotic over-prescription for diarrheal children under 5 years old without dysentery in Asembo $(N=2685)$

\begin{tabular}{|c|c|c|c|c|}
\hline Factors & $\begin{array}{l}\text { Antibiotic } \\
\text { prescribed (\%) }\end{array}$ & $\begin{array}{l}\text { Antibiotic not } \\
\text { prescribed (\%) }\end{array}$ & $\begin{array}{l}\text { Crude odds } \\
\text { ratio }(95 \% \text { Cl) }\end{array}$ & $\begin{array}{l}\text { Adjusted }{ }^{b} \text { odds } \\
\text { ratio }(95 \% \mathrm{Cl})\end{array}$ \\
\hline \multicolumn{5}{|l|}{ Demographics } \\
\hline Age $<1$ & $545 / 1410(38.3 \%)$ & $408 / 1275$ (32.0\%) & $1.32(1.13-1.55)$ & \\
\hline Male & 745/1410 (52.8\%) & 707/1275 (55.5\%) & $1.11(0.95-1.29)$ & \\
\hline \multicolumn{5}{|l|}{ Recent medical history } \\
\hline Clinic visit within 14 days & $182 / 1410(12.9 \%)$ & 127/1275 (10.0\%) & $1.34(1.05-1.70)$ & \\
\hline $\begin{array}{l}\text { Clinic visit within } 14 \text { days with } \\
\text { diarrheal symptom }\end{array}$ & 43/1406 (3.1\%) & $25 / 1270(2.0 \%)$ & $1.57(0.95-2.59)$ & \\
\hline $\begin{array}{l}\text { Clinic visit within } 14 \text { days with } \\
\text { antibiotic treatment }\end{array}$ & $64 / 1410(4.5 \%)$ & $42 / 1275(3.3 \%)$ & $1.40(0.94-2.08)$ & \\
\hline \multicolumn{5}{|l|}{ Signs and symptoms } \\
\hline Weight-for-age $<-2$ & 263/1395 (18.9\%) & 254/1262 (20.1\%) & $0.92(0.76-1.12)$ & \\
\hline Height-for-age $<-2$ & $369 / 1320(28.0 \%)$ & 324/1201 (27.0\%) & $1.05(0.88-1.25)$ & \\
\hline Weight-for-height $<-2$ & 182/1302 (14.0\%) & 182/1181 (15.4\%) & $0.89(0.71-1.11)$ & \\
\hline Measured or reported fever & $1158 / 1410(82.1 \%)$ & $1112 / 1275$ (87.2\%) & $0.67(0.54-0.83)$ & \\
\hline Cough & $691 / 1410(49.0 \%)$ & 601/1275 (47.1\%) & $1.08(0.93-1.25)$ & \\
\hline Difficulty breathing & $12 / 1409$ (0.9\%) & $11 / 1274(0.9 \%)$ & $0.99(0.43-2.24)$ & \\
\hline Sore throat & $12 / 1358(0.9 \%)$ & 4/1266 (0.3\%) & $2.81(0.90-8.72)$ & $5.03(0.73-34.91)$ \\
\hline Vomiting & 469/1410 (33.3\%) & 462/1272 (36.3\%) & $0.87(0.75-1.03)$ & $0.79(0.58-1.07)$ \\
\hline Runny nose & $477 / 1410$ (33.8\%) & 416/1275 (32.6\%) & $1.06(0.90-1.24)$ & \\
\hline Sneezing & $251 / 1409(17.8 \%)$ & 202/1275 (15.8\%) & $1.15(0.94-1.41)$ & \\
\hline \multicolumn{5}{|l|}{ Physical examination } \\
\hline Restless or irritable & $80 / 1409$ (5.7\%) & 46/1270 (3.6\%) & $1.60(1.11-2.32)$ & $1.39(0.81-2.40)$ \\
\hline Sunken eyes & 128/1408 (9.1\%) & 78/1270 (6.1\%) & $1.53(1.14-2.05)$ & $1.22(0.80-1.84)$ \\
\hline Drinks eagerly, thirsty & $58 / 1407$ (4.1\%) & $36 / 1268$ (2.8\%) & $1.47(0.96-2.25)$ & \\
\hline Skin tenting & $87 / 1405$ (6.2\%) & 46/1270 (3.6\%) & $1.76(1.22-2.53)$ & \\
\hline Signs of anemia & $30 / 1378$ (2.2\%) & $36 / 1243$ (2.9\%) & $0.75(0.46-1.22)$ & \\
\hline Crackles/rales & $3 / 1408(0.2 \%)$ & $6 / 1272(0.5 \%)$ & $0.45(0.11-1.81)$ & \\
\hline \multicolumn{5}{|l|}{ Clinical diagnoses } \\
\hline Gastroenteritis & $1292 / 1410$ (91.6\%) & 792/1275 (62.1\%) & $6.68(5.36-8.32)$ & $8.23(3.68-18.40)$ \\
\hline Malaria & $322 / 1410$ (22.8\%) & 660/1275 (51.8\%) & $0.27(0.23-0.33)$ & $0.37(0.25-0.54)$ \\
\hline Dehydration & $123 / 1410(8.7 \%)$ & $66 / 1275$ (5.2\%) & $1.75(1.28-2.39)$ & \\
\hline URTI & $415 / 1410$ (29.4\%) & 352/1275 (27.6\%) & $1.09(0.93-1.29)$ & \\
\hline \multicolumn{5}{|l|}{ Prescription } \\
\hline Concurrent $\mathrm{ORS}^{\mathrm{a}}$ & $1130 / 1410(80.1 \%)$ & 830/1275 (65.1\%) & $2.16(1.82-2.58)$ & $0.49(0.33-0.71)$ \\
\hline Concurrent zinc & $765 / 1410$ (54.3\%) & 714/1275 (56.0\%) & $0.93(0.80-1.09)$ & \\
\hline
\end{tabular}

aRTI Upper respiratory tract infection, ORS Oral rehydration solution

${ }^{\mathrm{b}}$ Adjusted by variables shown with adjusted $\mathrm{OR}$ and within-clinician variation

Odd ratio in bold indicates $p$-value $<0.05$

contributing to the emergence of antimicrobial resistance in Kenya $[25,26]$.

Factors associated with antibiotic over-prescription varied by site. In Asembo, diarrheal children were more likely to be prescribed with antibiotic when they were clinically diagnosed with gastroenteritis, suggesting that clinicians perceive acute diarrheal illness as an indication for antibiotics, despite IMCI and national guidelines recommend antibiotics only for bloody diarrhea. Furthermore, in Kibera, fever, cough, difficulty breathing and abnormal respiratory exam findings were associated with antibiotic over-prescription. This constellation of symptoms suggests that the observed antibiotic prescriptions may have been intended to treat respiratory infections. 
Table 2 Multivariate analysis for factors associated with antibiotic over-prescription for diarrheal children under 5 years old without dysentery in Kibera $(n=4518)$

\begin{tabular}{|c|c|c|c|c|}
\hline Factors & $\begin{array}{l}\text { Antibiotic } \\
\text { prescribed (\%) }\end{array}$ & $\begin{array}{l}\text { Antibiotic not } \\
\text { prescribed (\%) }\end{array}$ & $\begin{array}{l}\text { Crude odds } \\
\text { ratio }(95 \% \mathrm{Cl})\end{array}$ & $\begin{array}{l}\text { Adjusted }{ }^{b} \text { odds } \\
\text { ratio }(95 \% \mathrm{Cl})\end{array}$ \\
\hline \multicolumn{5}{|l|}{ Demographics } \\
\hline Age $<1$ & 194/904 (21.5\%) & $938 / 3614(26.0 \%)$ & $0.78(0.65-0.93)$ & $0.82(0.71-0.94)$ \\
\hline Male & 445/904 (49.2\%) & $1763 / 3614(48.8 \%)$ & $1.02(0.88-1.19)$ & \\
\hline \multicolumn{5}{|l|}{ Recent medical history } \\
\hline Clinic visit within 14 days & $111 / 904(12.3 \%)$ & $456 / 3614(12.6 \%)$ & $0.97(0.77-1.21)$ & \\
\hline $\begin{array}{l}\text { Clinic visit within } 14 \text { days with } \\
\text { diarrheal symptom }\end{array}$ & 40/872 (4.6\%) & $147 / 3446(4.3 \%)$ & $1.08(0.75-1.54)$ & \\
\hline $\begin{array}{l}\text { Clinic visit within } 14 \text { days with } \\
\text { antibiotic treatment }\end{array}$ & 39/904 (4.3\%) & $78 / 3614(2.2 \%)$ & $2.04(1.38-3.02)$ & $2.51(1.72-3.69)$ \\
\hline \multicolumn{5}{|l|}{ Signs and symptoms } \\
\hline Weight-for-age $<-2$ & $164 / 888(18.5 \%)$ & $625 / 3567(17.5 \%)$ & $1.07(0.88-1.29)$ & \\
\hline Height-for-age $<-2$ & $313 / 806(38.8 \%)$ & $1255 / 3010(41.7 \%)$ & $0.89(0.76-1.04)$ & \\
\hline Weight-for-height $<-2$ & $58 / 792(7.3 \%)$ & 233/2989 (7.8\%) & $0.94(0.69-1.26)$ & \\
\hline Measured or reported fever & 188/902 (20.8\%) & $360 / 3605$ (9.99\%) & $2.37(1.96-2.88)$ & $2.24(1.56-3.23)$ \\
\hline Cough & 505/904 (55.9\%) & $1667 / 3612(46.2 \%)$ & $1.48(1.28-1.71)$ & $1.42(1.06-1.90)$ \\
\hline Difficulty breathing & 8/865 (0.9\%) & $7 / 3185(0.2 \%)$ & $4.23(1.53-11.72)$ & $3.97(1.28-12.30)$ \\
\hline Sore throat & 6/901 (0.7\%) & $24 / 3599(0.7 \%)$ & $1.00(0.41-2.45)$ & \\
\hline Vomiting & 98/904 (10.8\%) & $575 / 3611(15.9 \%)$ & $0.64(0.51-0.81)$ & $0.74(0.53-1.03)$ \\
\hline Runny nose & 491/904 (54.3\%) & 1848/3612 (51.2\%) & $1.13(0.98-1.31)$ & \\
\hline Sneezing & 97/903 (10.7\%) & 480/3612 (13.3\%) & $0.79(0.62-0.99)$ & $0.74(0.40-1.38)$ \\
\hline \multicolumn{5}{|l|}{ Physical examination } \\
\hline Restless or irritable & 8/903 (0.9\%) & 33/3585 (0.9\%) & $0.96(0.44-2.09)$ & \\
\hline Sunken eyes & $11 / 904(1.2 \%)$ & $58 / 3591(1.6 \%)$ & $0.75(0.39-1.44)$ & \\
\hline Drinks eagerly, thirsty & $11 / 904(1.2 \%)$ & $33 / 3598(0.9 \%)$ & $1.33(0.67-2.64)$ & \\
\hline Skin tenting & 10/904 (1.1\%) & 45/3592 (1.3\%) & $0.88(0.44-1.76)$ & \\
\hline Signs of anemia & $1 / 901(0.1 \%)$ & 9/3598 (0.3\%) & $0.44(0.06-3.50)$ & \\
\hline Crackles/rales & $32 / 904$ (3.5\%) & $41 / 3614(1.1 \%)$ & $3.20(2.00-5.11)$ & $2.66(1.34-5.30)$ \\
\hline \multicolumn{5}{|l|}{ Clinical diagnoses } \\
\hline Gastroenteritis & 670/904 (74.1\%) & $2555 / 3588$ (71.2\%) & $1.16(0.98-1.37)$ & $1.62(0.94-2.80)$ \\
\hline Malaria diagnosis & 15/904 (2.0\%) & $94 / 3588(2.6 \%)$ & $0.63(0.36-1.09)$ & \\
\hline Dehydration & $5 / 904(0.6 \%)$ & $44 / 3588(1.2 \%)$ & $0.45(0.18-1.13)$ & \\
\hline $\mathrm{URTI}^{\mathrm{a}}$ & 415/904 (45.9\%) & $1651 / 3588$ (46.0\%) & $1.00(0.86-1.15)$ & $0.82(0.52-1.31)$ \\
\hline \multicolumn{5}{|l|}{ Treatment } \\
\hline Concurrent $\mathrm{ORS}^{\mathrm{a}}$ & 578/904 (63.9\%) & $2420 / 3614(67.0 \%)$ & $0.88(0.75-1.02)$ & $0.81(0.54-1.22)$ \\
\hline Concurrent zinc & 335/904 (37.1\%) & $1327 / 3614$ (36.7\%) & $1.02(0.87-1.18)$ & \\
\hline
\end{tabular}

aRTI Upper respiratory tract infection, ORS Oral rehydration solution

${ }^{\mathrm{b}}$ Adjusted by variables shown with adjusted $\mathrm{OR}$ and within-clinician variation Odd ratio in bold indicates $p$-value $<0.05$

However, for this analysis we excluded clinic visits in which patients met IMCI criteria for antibiotic treatment of pneumonia or very severe pneumonia, as well as visits with a discharge diagnosis of pneumonia. Thus, any antibiotics given for respiratory infections were likely unnecessary. Antibiotic overuse for acute respiratory infections in children is common [27] and must be addressed in conjunction with overuse for diarrheal illness.

Although antibiotic over-prescription is more commonly recognized as a public health threat, we also identified frequent under-prescription when antibiotics were indicated. This is especially concerning in resource-poor 
Table 3 Multivariate analysis for factors associated with antibiotic under-prescription for diarrheal children under 5 years old with dysentery in Western Kenya, Asembo $(n=123)$

\begin{tabular}{|c|c|c|c|c|}
\hline Factors & $\begin{array}{l}\text { Antibiotic } \\
\text { prescribed (\%) }\end{array}$ & $\begin{array}{l}\text { Antibiotic not } \\
\text { prescribed (\%) }\end{array}$ & $\begin{array}{l}\text { Crude odds } \\
\text { ratio }(95 \% \mathrm{Cl})\end{array}$ & $\begin{array}{l}\text { Adjusted }{ }^{\mathrm{b}} \text { odds } \\
\text { ratio }(95 \% \mathrm{Cl})\end{array}$ \\
\hline \multicolumn{5}{|l|}{ Demographics } \\
\hline Age $<1$ & 29/90 (32.2\%) & 12/33 (36.4\%) & $1.20(0.52-2.77)$ & \\
\hline Male & $50 / 90(55.6 \%)$ & 13/33 (39.4\%) & $0.52(0.23-1.17)$ & \\
\hline \multicolumn{5}{|l|}{ Recent medical history } \\
\hline Clinic visit within 14 days & $8 / 90(8.9 \%)$ & $3 / 33(9.1 \%)$ & $1.03(0.26-4.12)$ & \\
\hline $\begin{array}{l}\text { Clinic visit within } 14 \text { days with } \\
\text { diarrheal symptom }\end{array}$ & $4 / 90(4.4 \%)$ & $1 / 33(3.0 \%)$ & $0.67(0.07-6.24)$ & \\
\hline $\begin{array}{l}\text { Clinic visit within } 14 \text { days with } \\
\text { antibiotic treatment }\end{array}$ & $5 / 90(5.6 \%)$ & 0/33 (0\%) & N/A & \\
\hline \multicolumn{5}{|l|}{ Signs and symptoms } \\
\hline Weight-for-age $<-2$ & 17/89 (19.1\%) & 9/33 (27.3\%) & $1.59(0.63-4.03)$ & \\
\hline Height-for-age $<-2$ & 22/85 (25.9\%) & $6 / 30(20.0 \%)$ & $0.72(0.26-1.98)$ & \\
\hline Weight-for-height $<-2$ & $14 / 85(16.5 \%)$ & $5 / 30(16.7 \%)$ & $1.02(0.33-3.10)$ & \\
\hline Measured or reported fever & $81 / 90$ (90.0\%) & $31 / 33(93.9 \%)$ & $1.72(0.35-8.42)$ & \\
\hline Cough & $54 / 90(60.0 \%)$ & $22 / 33(66.7 \%)$ & $1.33(0.58-3.08)$ & \\
\hline Difficulty breathing & $1 / 90(1.1 \%)$ & 0/33 (0\%) & N/A & \\
\hline Sore throat & $1 / 89(0.9 \%)$ & 0/32 (0\%) & N/A & \\
\hline Vomiting & 23/90 (25.6\%) & 18/33 (54.5\%) & $3.50(1.52-8.04)$ & $4.36(1.98-9.57)$ \\
\hline Runny nose & 27/90 (30.0\%) & 10/33 (30.3\%) & $1.02(0.43-2.42)$ & \\
\hline Sneezing & 13/90 (14.4\%) & 6/33 (18.2\%) & $1.32(0.46-3.81)$ & \\
\hline \multicolumn{5}{|l|}{ Physical examination } \\
\hline Restless or irritable & $7 / 90(7.8 \%)$ & $2 / 33(6.1 \%)$ & $0.77(0.15-3.88)$ & \\
\hline Sunken eyes & $8 / 90(8.9 \%)$ & $3 / 33(12.1 \%)$ & $1.41(0.40-5.05)$ & \\
\hline Drinks eagerly, thirsty & $4 / 90(4.4 \%)$ & $1 / 33(3.0 \%)$ & $0.67(0.07-6.24)$ & \\
\hline Skin tenting & $4 / 90(4.4 \%)$ & 0/33 (0\%) & N/A & \\
\hline Signs of anemia & 4/88 (4.6\%) & 0/32 (0\%) & N/A & \\
\hline Crackles/rales & 0/90 (0\%) & 0/33 (0\%) & N/A & \\
\hline \multicolumn{5}{|l|}{ Clinical diagnoses } \\
\hline Gastroenteritis & 42/90 (45.6\%) & 10/33 (30.3\%) & $0.52(0.22-1.22)$ & \\
\hline Malaria diagnosis & 29/90 (32.2\%) & 18/33 (54.6\%) & $2.52(1.12-5.71)$ & $1.82(1.05-3.13)$ \\
\hline Dehydration & 3/90 (3.3\%) & 3/33 (9.1\%) & $2.90(0.56-15.13)$ & \\
\hline $\mathrm{URTI}^{\mathrm{a}}$ & 20/90 (22.2\%) & 8/33 (24.2\%) & $1.12(0.44-2.86)$ & \\
\hline Dysentery & 47/90 (52.2\%) & $8 / 33(24.2 \%)$ & $0.29(0.12-0.72)$ & $0.30(0.07-1.24)$ \\
\hline \multicolumn{5}{|l|}{ Treatment } \\
\hline Concurrent $\mathrm{ORS}^{\mathrm{a}}$ & $59 / 90(65.6 \%)$ & 14/33 (42.4\%) & $0.39(0.17-0.88)$ & $0.34(0.10-1.19)$ \\
\hline Concurrent zinc & $41 / 90(45.6 \%)$ & 15/33 (45.5\%) & $1.00(0.45-2.22)$ & \\
\hline
\end{tabular}

${ }^{a}$ URTI Upper respiratory tract infection, ORS Oral rehydration solution

${ }^{\mathrm{b}}$ Adjusted by variables shown with adjusted $\mathrm{OR}$ and within-clinician variation

Odd ratio in bold indicates $p$-value $<0.05$

settings like Kenya where the burden of infectious diseases still remains high, access to care is not always optimal, and essential drugs may not readily be available. A study evaluating the appropriateness of antibiotic use per IMCI guidelines in Papua New Guinea reported that $11 \%$ of children in outpatient settings did not receive

antibiotics when they should have [28]. In our study, approximately 1 in 4 dysentery cases in Asembo and 3 in 4 cases in Kibera went untreated. Shigella is a common cause of bloody diarrhea and has been previously isolated from the stool of $36 \%$ of persons with dysentery in Nairobi [29], and 43.9\% in rural western Kenya [30]. 
Table 4 Multivariate analysis for factors associated with antibiotic under-prescription for diarrheal children under 5 years old with dysentery in Nairobi, Kibera $(n=179)$

\begin{tabular}{|c|c|c|c|c|}
\hline Factors & $\begin{array}{l}\text { Antibiotic } \\
\text { prescribed (\%) }\end{array}$ & $\begin{array}{l}\text { Antibiotic not } \\
\text { prescribed }(\%)\end{array}$ & $\begin{array}{l}\text { Crude odds } \\
\text { ratio }(95 \% \mathrm{Cl})\end{array}$ & $\begin{array}{l}\text { Adjusted }{ }^{\mathrm{b}} \text { odds } \\
\text { ratio }(95 \% \mathrm{Cl})\end{array}$ \\
\hline \multicolumn{5}{|l|}{ Demographics } \\
\hline Age $<1$ & $4 / 47(8.51 \%)$ & 33/132 (25.0\%) & $3.58(1.20-10.72)$ & $4.76(1.46-15.50)$ \\
\hline Male & $21 / 47$ (44.7\%) & 73/132 (55.3\%) & $1.53(0.78-2.99)$ & \\
\hline \multicolumn{5}{|l|}{ Recent medical history } \\
\hline Clinic visit within 14 days & $7 / 47(14.9 \%)$ & 21/132 (15.9\%) & $1.08(0.43-2.74)$ & \\
\hline $\begin{array}{l}\text { Clinic visit within } 14 \text { days with } \\
\text { diarrheal symptom }\end{array}$ & $3 / 45(6.7 \%)$ & $8 / 127(6.3 \%)$ & $0.94(0.24-3.71)$ & \\
\hline $\begin{array}{l}\text { Clinic visit within } 14 \text { days with } \\
\text { antibiotic treatment }\end{array}$ & $1 / 47(2.1 \%)$ & 3/132 (2.3\%) & $1.07(0.11-10.51)$ & \\
\hline \multicolumn{5}{|l|}{ Signs and symptoms } \\
\hline Weight-for-age $<-2$ & $8 / 47(17.0 \%)$ & 21/132 (15.9\%) & $0.92(0.38-2.25)$ & \\
\hline Height-for-age $<-2$ & 23/42 (54.8\%) & 46/106 (43.4\%) & $0.63(0.31-1.30)$ & \\
\hline Weight-for-height $<-2$ & $3 / 42(7.1 \%)$ & 7/106 (6.6\%) & $0.92(0.23-3.74)$ & \\
\hline Measured or reported fever & $8 / 47(17.0 \%)$ & 13/132 (9.85\%) & $0.53(0.21-1.38)$ & $0.34(0.11-1.05)$ \\
\hline Cough & 25/47 (53.2\%) & $55 / 132(41.7 \%)$ & $0.63(0.32-1.22)$ & $0.54(0.25-1.17)$ \\
\hline Difficulty breathing & $1 / 43(2.33 \%)$ & 0/107 (0\%) & N/A & \\
\hline Sore throat & 0/47 (0\%) & 0/131 (0\%) & N/A & \\
\hline Vomiting & $5 / 47(10.6 \%)$ & 8/132 (6.1\%) & $0.54(0.17-1.75)$ & \\
\hline Runny nose & 27/47 (57.5\%) & 63/132 (47.7\%) & $0.68(0.35-1.32)$ & \\
\hline Sneezing & $6 / 47(12.7 \%)$ & 16/132 (12.1\%) & $0.94(0.35-2.57)$ & \\
\hline \multicolumn{5}{|l|}{ Physical examination } \\
\hline Restless or irritable & 0/47 (0\%) & 0/131 (0\%) & $\mathrm{N} / \mathrm{A}$ & \\
\hline Sunken eyes & $1 / 47(2.1 \%)$ & 0/132 (0\%) & N/A & \\
\hline Drinks eagerly, thirsty & $2 / 47(4.3 \%)$ & 0/132 (0\%) & N/A & \\
\hline Skin tenting & $1 / 47(2.1 \%)$ & 0/131 (0\%) & N/A & \\
\hline Signs of anemia & $0 / 47(0 \%)$ & 1/131 (0.8\%) & N/A & \\
\hline Crackles/rales & 0/47 (0\%) & 1/132 (0.8\%) & $\mathrm{N} / \mathrm{A}$ & \\
\hline \multicolumn{5}{|l|}{ Clinical diagnoses } \\
\hline Gastroenteritis & $32 / 47$ (68.1\%) & 79/131 (60.3\%) & $0.71(0.35-1.44)$ & \\
\hline Malaria diagnosis & $1 / 47(2.1 \%)$ & 2/131 (1.5\%) & $0.71(0.06-8.05)$ & \\
\hline Dehydration & $1 / 47(2.1 \%)$ & $1 / 131(0.8 \%)$ & $0.35(0.02-5.78)$ & \\
\hline URTI ${ }^{a}$ & $14 / 47(29.8 \%)$ & 40/131 (30.5\%) & $1.04(0.50-2.14)$ & \\
\hline Dysentery & 13/47 (27.7\%) & 7/131 (5.3\%) & $0.15(0.06-0.40)$ & $0.10(0.03-0.34)$ \\
\hline \multicolumn{5}{|l|}{ Treatment } \\
\hline Concurrent $\mathrm{ORS}^{\mathrm{a}}$ & $37 / 47(78.7 \%)$ & $83 / 132(62.9 \%)$ & $0.46(0.21-1.00)$ & \\
\hline Concurrent zinc & 15/47 (31.9\%) & 42/132 (31.8\%) & $1.00(0.49-2.03)$ & \\
\hline
\end{tabular}

URTI=Upper respiratory tract infection, ORS=Oral rehydration solution

${ }^{\mathrm{b}}$ Adjusted by variables shown with adjusted OR and within-clinician variation

Odd ratio in bold indicates $p$-value $<0.05$

Moreover, stool culture unlike molecular testing, may underestimate the true burden of Shigella [31]. Thus, failure to treat dysentery with antibiotics represents a missed opportunity to reduce Shigella-related morbidity and prevent further spread of such infections in the community. In Kibera, a discharge diagnosis of dysentery

was negatively associated with under-prescription, suggesting that clinician recognition of dysentery cases can improve adherence to recommended management.

In Asembo, a discharge diagnosis of malaria was inversely associated with antibiotic over-prescription but positively associated with antibiotic under-prescription. 


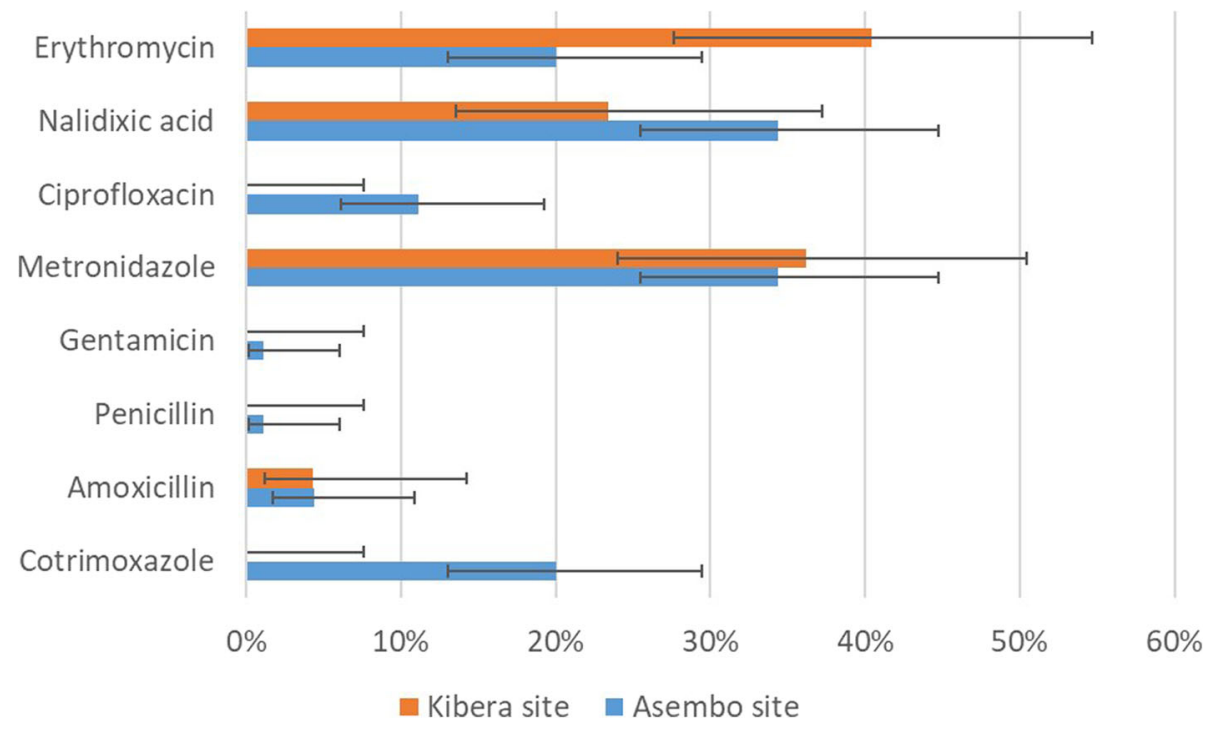

Fig. 2 Proportion and 95\% confidence interval of commonly prescribed antibiotics for diarrhea with dysentery. Antibiotics are not mutually exclusive

Per IMCI guidelines, a child meeting the case definition for malaria and dysentery should be treated for both. However, malaria diagnosis has been reported to increase untargeted antibiotic use [32] and affect clinician's ability to detect other concurrent infections. A study of adherence to IMCI guidelines in Tanzania reported that health workers consistently provided recommended therapy for a single diagnosis, but rarely diagnosed or treated more than one condition [33]. A study in Mozambique found a diagnosis of malaria to be leading risk factor for failure to treat pneumonia [34]. Proper adherence to IMCI guidelines is important for avoiding unnecessary antibiotic use, but also to ensure that patients who should be treated with antibiotics receive them appropriately.

Correct choice of antibiotic agent is an important component of rational use. Although ciprofloxacin is the recommended antibiotic for dysentery in Kenya [13], the most commonly prescribed antibiotics for dysentery were metronidazole, erythromycin, and nalidixic acid.

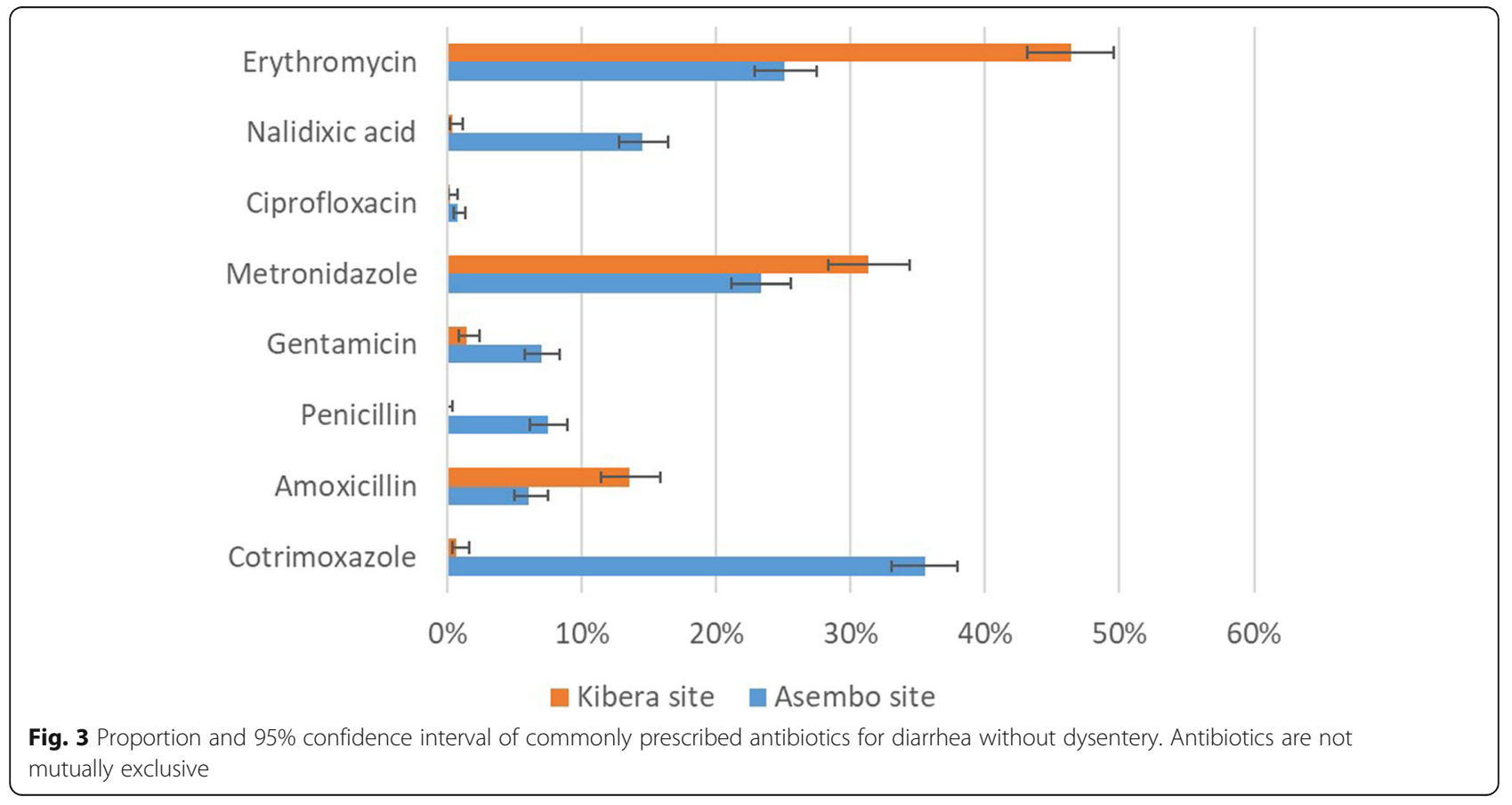


Metronidazole and erythromycin are not effective in treating shigellosis [17] and nalidixic acid, previously used as the first-line antibiotic against Shigella, is no longer recommended by the WHO, even in areas where Shigella remains susceptible [16]. Previous studies in Kenya have found Shigella to be susceptible to nalidixic acid $[35,36]$, however ciprofloxacin has a greater activity against Enterobacteriacae than nalidixic acid and less chance of inducing resistance in Shigella and other pathogens [16]. Although there are safety concerns, especially musculoskeletal adverse events, surrounding use of newer quinolones in pediatric patients [37], the WHO has deemed the benefits to outweigh the risk, but lingering concern about safety of ciprofloxacin in children may contribute to suboptimal choice of antibiotic for treating pediatric dysentery [16]. Thus adherence to the recommendation of ciprofloxacin for treatment of dysentery is important for prevention of antimicrobial resistance.

Our findings have limited generalizability as the data are from only two private health facilities with on-going disease surveillance and research activities. It is likely that inappropriate antibiotic prescribing in other facilities is more common than what we observed. We relied on data documented in the medical record; inaccurate recording of key data may have led to misclassification of antibiotic indications and factors associated with overor under-prescription. Although the IMCI guideline recommends antibiotic treatment for diarrheal illness with a severe dehydration in the region with circulating cholera [38], we did not consider this within our study. Kenya has experienced outbreaks of cholera in 20072010 [39], 2014 to the present [40] and these outbreaks may have contributed to antibiotic over-prescription. However, there were very few confirmed cholera cases within the surveillance population during the study period. Moreover, due to the exclusion of records with non-diarrheal indications for antibiotics, only $1 \%$ of the included diarrheal visits were complicated by severe dehydration. Thus, cholera is unlikely to have been an important consideration in assessing use of antibiotics for childhood diarrhea. Lastly, a small number of dysentery cases may have slightly biased estimates of odds ratio for factors associated with antibiotic under-prescription.

Despite these limitations, our findings indicate that inappropriate antibiotic prescription for childhood diarrhea might be common in Kenya. Further assessment of the magnitude of inappropriate antibiotic use in a broader range of facilities and geographic locations, and to provide more insight into the factors that shape antibiotic prescription for children with diarrhea. Furthermore, in Asembo, 14\% of children were given antibiotics by the caretaker before seeking care from healthcare facilities [41], suggesting future studies should also consider inappropriate antibiotic use before seeking medical care. Based on our findings, antibiotic stewardship interventions for outpatient diarrheal case management should address all aspects of inappropriate antibiotic use, including over- prescription, under-prescription and optimal choice of antibiotic agent. Strategies might include providing routine trainings on appropriate antibiotic use followed by supportive supervision and quality assurance review [42-44]. Global efforts to improve outpatient malaria diagnostic capacity should be continued with an emphasis on recognizing concurrent infections, including dysentery.

\section{Conclusions}

Diarrhea is one of the most common reasons for children to seek medical attention in Kenya and globally; inappropriate antibiotic prescription for childhood diarrhea is an important and modifiable contributor to the growing public health threat of antimicrobial resistance.

\section{Additional file}

\begin{abstract}
Additional file 1: Table S1. and Table S2. Symptoms and signs used to define each non-diarrheal indications for antibiotics among children aged 2-59 months per Integrated Management for Childhood Illness (IMCI) guidelines are shown on Table S1. Data on multivariate analysis for factors associated with antibiotic over-prescription among diarrheal children under 5 years old without dysentery in Western Kenya, Asembo are shown on Table S2. (DOCX $17 \mathrm{~kb}$ )
\end{abstract}

\section{Abbreviations}

CDC: U.S. Centers for Disease Control and Prevention; IMCI: Integrated Management of Childhood IIIness; KEMRI: Kenya Medical Research Institute; PBIDS: Population-Based Infectious Disease Surveillance; WHO: World Health Organization

\section{Acknowledgements}

We thank the Population-Based Infectious Disease Surveillance (PBIDS) and the U.S. Centers for Disease Control and Prevention staff who participated in data collection, training, and other implementation activities during the study period. We also thank the PBIDS participants for their willingness to share information about their illnesses.

The findings and conclusions in this report are those of the authors and do not necessarily represent the official position of the U.S. Centers for Disease Control and Prevention.

\section{Funding}

This work was supported by the Global Disease Detection Program, Center for Global Health at the U.S. Centers for Disease Control and Prevention.

\section{Availability of data and materials}

The datasets used and analyzed during the current study are available from the corresponding author on reasonable request through the Kenya Medical Research Institute Centre for Global Health Research.

\section{About this supplement}

This article has been published as part of BMC Public Health Volume 19 Supplement 3, 2019: 10th anniversary of the Centers for Disease Control and Prevention - Global Disease Detection program. The full contents of the supplement are available online at https://bmcpublichealth.biomedcentral. com/articles/supplements/volume-19-supplement-3. 


\section{Authors' contributions}

$\mathrm{CR}, \mathrm{GB}, \mathrm{RO}, \mathrm{JMM}$ and JRV conceived and designed the study. GA, AO, SM, JA $A A, G O$ were responsible for data management, and CR, JRV, REW for statistical analyses. JRV, JMM, MAW oversaw the overall PBIDS and GA, AO, $A A, R O, G B$ led the surveillance enrollment and study site management. $C R$ JRV, CEO, MAW, and RO contributed to writing the manuscript. All authors critically reviewed the manuscript. All authors read and approved the final manuscript.

\section{Ethics approval and consent to participate}

The surveillance protocol and questionnaires were reviewed and approved by the institutional review boards of the Kenya Medical Research Institute (Protocol \#932 and \#1899) and U.S. Centers for Disease Control and Prevention (Protocol \#4566). Written informed consent for data collection was obtained from heads of household of all surveillance participants at the time of their enrollment. Written informed consent for each individual was obtained prior to sample collection; for minors, written informed consent for sample collection was obtained from their parent or guardian.

\section{Consent for publication}

Not applicable.

\section{Competing interests}

The authors declare that they have no competing interests.

\section{Publisher's Note}

Springer Nature remains neutral with regard to jurisdictional claims in published maps and institutional affiliations.

\section{Author details}

'Division of Global Health Protection, Center for Global Health, Centers for Disease Control and Prevention, Atlanta, GA, USA. ${ }^{2}$ Center for Global Health Research, Kenya Medical Research Institute, Kisumu, Kenya. ${ }^{3}$ Center for Global Health Research, Kenya Medical Research Institute, Nairobi, Kenya. ${ }^{4}$ Division of Global Health Protection, Centers for Disease Control and Prevention, Nairobi, Kenya. ${ }^{5}$ Division of Foodborne, Waterborne, and Environmental Diseases, National Center for Emerging and Zoonotic Infectious Disease, Centers for Disease Control and Prevention, Atlanta, GA, USA.

\section{Published: 10 May 2019}

\section{References}

1. World Health Organization. Antimicrobial resistance fact sheet. Geneva, 2017. (Available at: http://www.who.int/mediacentre/factsheets/fs194/en/) Accessed 13 Nov 2017

2. World Health Organization. WHO essential medicines and health product, annual report 2015. Geneva, 2016. (Available at: http://www.who.int/ medicines/publications/emp_annual-report2015/en/ Accessed 13 Nov 2017.

3. World Health Organization. WHO antimicrobial resistance global report on surveillance. Geneva, 2014. (Available at: http://www.who.int/antimicrobialresistance/publications/surveillancereport/en/) Accessed 13 Nov 2017.

4. World Health Organization. Global action plan on antimicrobial resistance. Geneva, 2015. (Available at: http://www.who.int/antimicrobial-resistance/ publications/global-action-plan/en/) Accessed 13 Nov 2017

5. World Health Organization. Promoting rational use of medicines: Core components - WHO policy perspectives on medicines. Geneva, 2002 (Available at: http://apps.who.int/medicinedocs/pdf/h3011e/h3011e.pdf) Accessed 13 Nov 2017

6. Spellberg B, Blaser M, Guidos RJ, et al. Combating antimicrobial resistance: policy recommendations to save lives. Clin Infect Dis. 2011;52(Suppl 5): S397-428.

7. World Health Organization/United Nations Children's Fund. Handbook: IMCI integrated management of childhood illness. Geneva, 2005. (Available at: http://apps.who.int/iris/handle/10665/42939) Accessed 13 Nov 2017.

8. World Health Organization. Integrated Management of Childhood Illness for high HIV settings. Geneva, 2008. (Available at: http://apps.who.int/iris/ handle/10665/44010) Accessed 13 Nov 2017

9. World Health Organization/United Nations Children's Fund. Clinical Management of Acute Diarrhoea. Geneva, 2004. (Available at: http://www. who.int/child_adolescent health/documents/who fch_cah_04_7/en/index html) Accessed 13 Nov 2017
10. World Health Organization. The treatment of diarrhea; a manual for physicians and other senior health workers. Geneva, 2005. (Available at: http://apps.who. int/iris/bitstream/10665/43209/1/9241593180.pdf) Accessed 13 Nov 2017.

11. GBD 2015 Child Mortality Collaborators. Global, Regional, National, and Selected Subnational Levels of Stillbirths, Neonatal, Infant, and Under-5 Mortality, 1980-2015: a Systematic Analysis for the Global Burden of Disease Study 2015. Lancet. 2016;388(10053):1725-74.

12. Kotloff KL, Nataro JP, Blackwelder WC, et al. Burden and Aetiology of Diarrhoeal disease in infants and young children in developing countries (the global enteric multicenter study, GEMS): a prospective, case-control study. Lancet. 2013;382(9888):209-22.

13. Kenya Ministry of Health. Policy Guidelines for Management of Diarrhoea in Children Below Five Years in Kenya. 2015. (Available at: http://guidelines. health.go.ke:8000/media/Policy_Guidelines_for_Management_of_Diarrhoea_ in Children_Below.pdf) Accessed 13 Nov 2017.

14. GARP-Kenya Working Group. Situation analysis and recommendations; antibiotic use and resistance in Kenya. 2011 (Available at: http://cddep.org/ wp-content/uploads/2017/08/garp-kenya_sa.pdf) Accessed 13 Nov 2017.

15. Feikin DR, Olack B, Bigogo GM, et al. The burden of common infectious disease syndromes at the clinic and household level from population-based surveillance in rural and urban Kenya. PLoS One. 2011:6(1):e16085.

16. World Health Organization/United Nations Children's Fund. Handbook: IMCI integrated management of childhood illness, 2005 technical update. Geneva, 2005. (Available at: http://www.who.int/maternal_child_adolescent/ documents/9241593482/en/) Accessed 13 Nov 2017.

17. World Health Organization. Guidelines for the control of shigellosis, including epidemics due to Shigella dysenteriae type 1. Geneva, 2005 (Available at: http://www.who.int/cholera/publications/shigellosis/en/) Accessed 13 Nov 2017.

18. Tibshirani R. Regression shrinkage and selection via the lasso. J R Statist Soc B. 1996;58(1):267-88.

19. Liang KY, Zeger S. Longitudinal data analysis using generalized linear models. Biometrika. 1986;73(1):13-22.

20. Gwimile JJ, Shekalaghe SA, Kapanda GN, Kisanga ER. Antibiotic prescribing practice in Management of Cough and/or Diarrhoea in Moshi municipality, northern Tanzania: cross-sectional descriptive study. Pan Afr Med J. 2012:12: 103. https://doi.org/10.11604/pamj.2012.12.103.1716.

21. Pathak D, Pathak A, Marrone G, Diwan V, Lundborg CS. Adherence to treatment guidelines for acute Diarrhoea in children up to 12 years in Ujjain, India--a cross-sectional prescription analysis. BMC Infect Dis. 2011;11: 32. https://doi.org/10.1186/1471-2334-11-32.

22. Osatakul S, Puetpaiboon A. Appropriate use of empirical antibiotics in acute Diarrhoea: a cross-sectional survey in southern Thailand. Ann Trop Paediatr. 2007:27(2):115-22.

23. Gu J, Zhao J, Huang $Y$, et al. Use of antibiotics by urban and rural residents in Heilongjiang Province, China: cross-sectional study. Tropical Med Int Health. 2015:20(12):1815-22.

24. Gebeyehu E, Bantie L, Azage M. Inappropriate use of antibiotics and its associated factors among urban and rural communities of Bahir Dar City Administration, Northwest Ethiopia. PLoS One. 2015;10(9):e0138179.

25. Omulo S, Thumbi SM, Njenga MK, Call DR. A review of 40 years of enteric antimicrobial resistance research in eastern Africa: what can be done better? Antimicrob Resist Infect Control. 2015:4:1. https://doi.org/10.1186/ s13756-014-0041-4.

26. Tadesse BT, Ashley EA, Ongarello $S$, et al. Antimicrobial resistance in Africa: a systematic review. BMC Infect Dis. 2017;17(1):616. https://doi.org/10.1186/ s12879-017-2713-1.

27. Rogawski ET, Platts-Mills JA, Seidman JC, et al. Use of antibiotics in children younger than two years in eight countries: a prospective cohort study. Bull. World Health Organ. 2017;95(1):49-61.

28. Senn N, Rarau P, Salib M, et al. Use of antibiotics within the IMCI guidelines in outpatient settings in Papua new Guinean children: an observational and effectiveness study. PLoS One. 2014;9(3):e90990.

29. Njuguna HN, Cosmas L, Williamson J, et al. Use of population-based surveillance to define the high incidence of shigellosis in an urban slum in Nairobi, Kenya. PLoS One. 2013:8(3):e58437.

30. Brooks JT, Shapiro RL, Kumar L, et al. Epidemiology of sporadic bloody diarrhea in rural Western Kenya. Am J Trop Med Hyg. 2003;68(6):671-7.

31. Liu J, Platts-Mills JA, Juma J, et al. Use of quantitative molecular diagnostic methods to identify causes of Diarrhoea in children: a reanalysis of the GEMS case-control study. Lancet. 2016;388(10051):1291-301. 
32. Hopkins H, Bruxvoort KJ, Cairns ME, et al. Impact of introduction of rapid diagnostic tests for malaria on antibiotic prescribing: analysis of observational and randomised studies in public and private healthcare settings. BMJ. 2017;356:j1054. https://doi.org/10.1136/bmj.j1054.

33. Reyburn H, Mbatia R, Drakeley C, et al. Overdiagnosis of malaria in patients with severe febrile illness in Tanzania: a prospective study. BMJ. 2004; 329(7476):1212. https://doi.org/10.1136/bmj.38251.658229.55.

34. Acácio S, Verani JR, Lanaspa M, et al. Under treatment of pneumonia among children under 5 years of age in a malaria-endemic area: population-based surveillance study conducted in Manhica District- rural, Mozambique. Int J Infect Dis. 2015;36:39-45.

35. Sang WK, Oundo V, Schnabel D. Prevalence and antibiotic resistance of bacterial pathogens isolated from childhood Diarrhoea in four provinces of Kenya. J Infect Dev Ctries. 2012;6(7):572-8.

36. Brooks JT, Ochieng JB, Kumar L, et al. Surveillance for bacterial diarrhea and antimicrobial resistance in rural Western Kenya, 1997-2003. Clin Infect Dis. 2006;43(4):393-401.

37. Adefurin A, Sammons H, Jacqz-Aigrain E, Choonara I. Ciprofloxacin safety in Paediatrics: a systematic review. Arch Dis Child. 2011;96(9):874-80.

38. United Nations Children's Fund. Cholera Toolkit. New York, 2013. (Available at: https:/www.unicef.org/cholera/index_71222.html) Accessed 13 Nov 2017.

39. Mutonga $D$, Langat $D$, Mwangi $D$, et al. National surveillance data on the epidemiology of cholera in Kenya, 1997-2010. J Infect Dis. 2013;208(Suppl 1):S55-61.

40. George G, Rotich J, Kigen $\mathrm{H}$, et al. Notes from the field: ongoing cholera outbreak - Kenya, 2014-2016. MMWR Morb Mortal Wkly Rep. 2016;65(3):68-9.

41. Omore R, O'Reilly CE, Williamson J, et al. Health care-seeking behavior during childhood diarrheal illness: results of health care utilization and attitudes surveys of caretakers in Western Kenya, 2007-2010. Am J Trop Med Hyg. 2013:89(1 Suppl):29-40.

42. Sanchez GV, Fleming-Dutra KE, Roberts RM, Hicks LA. Core elements of outpatient antibiotic stewardship. MMWR Recomm Rep. 2016;65(6):1-12.

43. Nguyen DT, Leung KK, Mclntyre L, Ghali WA, Sauve R. Does integrated Management of Childhood IIIness (IMCI) training improve the skills of health workers? A systematic review and meta-analysis. PLoS One. 2013;8(6):e66030

44. Gera T, Shah D, Garner P, Richardson M, Sachdev HS. Integrated Management of Childhood Illness (IMCI) strategy for children under five. Cochrane Database Syst Rev. 2016;6:CD010123.

Ready to submit your research? Choose BMC and benefit from:

- fast, convenient online submission

- thorough peer review by experienced researchers in your field

- rapid publication on acceptance

- support for research data, including large and complex data types

- gold Open Access which fosters wider collaboration and increased citations

- maximum visibility for your research: over $100 \mathrm{M}$ website views per year

At $\mathrm{BMC}$, research is always in progress.

Learn more biomedcentral.com/submissions 